\title{
"With Age Comes Wisdom:" a Qualitative Review of Elder Perspectives on Healthy Aging in the Circumpolar North
}

\author{
Britteny M. Howell ${ }^{1,2}$ (D) Jennifer R. Peterson ${ }^{2,3}$ \\ Published online: 07 May 2020 \\ (C) Springer Science+Business Media, LLC, part of Springer Nature 2020
}

\begin{abstract}
Cross-cultural research has shown marked variation in health outcomes across the world's older adult populations. Indeed, older adults in the Circumpolar North experience a variety of health disparities. Because aging is a biological process rooted in sociocultural context, there exists great variation in the ways older adults define and experience healthy, or "successful," aging in their communities. The aim of this analysis was to synthesize qualitative research among older residents (aged 50+ years) in the Circumpolar North to identify a definition of healthy aging common in the region. A thorough review was conducted across a variety of academic search databases for peer-reviewed, qualitative studies conducted among communitydwelling older adults. The search strategy initially identified 194 articles; 23 articles met the inclusion criteria. Included studies were coded and analyzed using Grounded Theory to examine underlying themes of healthy aging in the Circumpolar North. The findings reveal the importance older adults place on respect, their relationship to the land, and psychosocial resilience into multidimensional models of healthy aging. This research also highlights the need for increased translational research with populations in the Circumpolar North that are under-represented in the literature.
\end{abstract}

Keywords Qualitative $\cdot$ Lay perspectives $\cdot$ Healthy aging $\cdot$ Successful aging $\cdot$ Subarctic $\cdot$ Arctic

Britteny M. Howell

bmhowel12@alaska.edu

1 Division of Population Health Sciences, University of Alaska Anchorage, 3211 Providence Drive, BOC3 \#233, Anchorage, AK 99508, USA

2 National Resource Center for Alaska Native Elders, University of Alaska Anchorage, Anchorage, AK, USA

3 Department of Psychology, University of Alaska Fairbanks, Fairbanks, AK, USA 


\section{Introduction}

Cross-cultural research has shown marked variation in health outcomes across the world's older adult populations (Bardage et al. 2005; Kowal et al. 2010; Zunzunegui et al. 2009). Older people living in the Circumpolar North experience a variety of health disparities that include increased incidence of obesity, cardiovascular disease, mental illness, suicide, and rising rates of cancer when compared to their more southern counterparts (Abarca-Gómez et al. 2017; Bjerregaard and Dahl-Petersen 2011; Bourque and Cunsolo Willox 2014; Cunsolo Willox et al. 2015; Emelyanova and Rautio 2016; Johnson et al. 2009; Liu et al. 2006; Redvers et al. 2015; Young et al. 2016). Older adults in the Circumpolar North receive routine medical checkups less frequently and indicate poorer self-reported health status than more southern residents (Begum and Naskali 2016; Emelyanova et al. 2010; Foutz et al. 2016; Kachan et al. 2014; Naskali et al. 2019).

These inequities in the Circumpolar North may be the consequence of unique socioeconomic and environmental circumstances that have resulted in lower health literacy, lack of access to high quality healthcare, and greater food insecurity when compared to many other world regions (Brega et al. 2012; Driscoll et al. 2013; IPCC 2014; Sharma 2010; Smith et al. 2009). For example, the changing climate in the region has been linked to population displacement, reduced access to hunted and traditional foods, environmental contaminants, and greater risk of injury, disease, and mortality from extreme weather events (Abass et al. 2018; Aslaksen et al. 2008; IPCC 2014; Loring and Gerlach 2009; Mead et al. 2010; Mikow et al. 2019; Waits et al. 2018). In addition to the unique physical environment, a variety of sociocultural conditions appear to have a significant effect on aging outcomes, such as increased risk of social isolation and declining respect for the wisdom of elders among the younger generations in the Circumpolar North (Driscoll et al. 2013; Hopkins et al. 2007; Miyawaki 2015). Both the physical and social environments impact what people may believe contributes to "healthy aging."

However, there is no universal definition of exactly what constitutes healthy aging. The phrase "successful aging" is often used to describe healthy aging in terms of three main components: low probability of disease and disease-related disability, high cognitive and physical functional capacity, and active engagement with life (Rowe and Kahn 1997). Researchers tend to rely on maintenance of physical and mental functioning to define healthy aging. However, researcher-driven models of healthy aging have been labeled by some as ageist because they often exclude many older adults and may further stigmatize and marginalize them, especially those with disabilities (Minkler and Fadem 2002). Community members, in contrast, tend to describe many diverse domains to conceptualize wellbeing, such as psychosocial components of aging, despite age-related limitations (Cosco et al. 2013; Hung et al. 2010). Indeed, at least one study has shown that important domains of healthy aging conceptualized by older adults can be mutually exclusive of the domains created by researchers, with no overlap or agreement at all (Kusumastuti et al. 2016).

The concept of "active ageing" has become increasingly popular in the European Union; however, this concept also has no universally accepted definition (Boudiny 2013). Since the 1980s, research and policy in the EU has shifted away from negative views of old age linked to rest and retirement, and moved toward defining healthy aging as continued engagement in society and the workforce (Bowling 2005). The World Health Organization defines active ageing as "the process of optimizing opportunities for health, participation, and security in order to enhance quality of life as people age" (WHO 2002: 12). Although differing definitions 
abound, the term active ageing appears most often to be rooted in the consequences of population aging for public finances (see Boudiny 2013 for a thorough review). This has resulted in much active ageing research and policy focusing on physical health, physical activity, and employment status with the aim of lowering demand for healthcare services (Liotta et al. 2018).

Because aging is a biological process rooted in sociocultural context, there is variation in the ways different groups of people define and think about aging in their communities (Löckenhoff et al. 2009). Such lay perspectives are not as common in the aging literature as professional definitions that operationalize biomedical health indicators. Little research has addressed the question of healthy aging from an emic (insider's) point of view, one that seeks to understand how the sociocultural environment of a specific community can shape the ways in which people conceptualize what constitutes a good old age (Collings 2001). Cross-cultural research suggests that not all older adults think about healthy aging in the individualistic way that is often defined by Western biomedical practitioners; however, the current literature underrepresents non-Western countries and largely includes culturally homogenous research participants (Cosco et al. 2013). Indeed, the current literature lacks a synthesis of healthy aging in the diverse expanse of the Circumpolar North, where social and environmental influences on aging may differ markedly from other regions of the world.

In this paper, healthy or successful aging refers to the process of change during senescence that allows the individual to continually modify lifestyles, assess strengths, and redefine oneself in meaningful ways in relation to their health, families, and communities (HansenKyle 2005). The Circumpolar North is defined as the Arctic and subarctic regions of Canada, Finland, Denmark, Greenland \& the Faroe Islands, Iceland, Norway, Russia, Sweden, and the United States (The University of the Arctic 2018). Because this is such a large geographical region, research studies tend to be very fragmented: often divided by country, physical environment (i.e. urban vs. rural), or by ethnic group (i.e. studies focusing only on Indigenous or specific immigrant populations). The concept of active ageing is excluded from this analysis because its focus on lowering the burden that older adults place on public finances puts it outside of the scope of our research question on how older adults perceive having a good old age.

The aim of this study is to synthesize the qualitative literature regarding how older adults define healthy aging in the Circumpolar North to identify the domains that may be unique to this region of the world. Research shows that when respondents create lay models of their community health issues these models are more robust and inclusive, delineating a variety of factors that contribute to aging patterns that are not always captured by researcher-driven models (Bowling 2006; Cosco et al. 2013; Entwistle et al. 1998). These are important perspectives because the ways culturally diverse older adults conceptualize healthy aging has a significant relationship to the practices they uphold and their health outcomes (Torres 2003). Additionally, these perspective can better inform culturally-appropriate practices among health care professionals and elder care workers that may improve quality of life outcomes.

\section{Methods}

A systematic search was conducted for peer-reviewed articles across Google Scholar, PubMed, MEDLINE, CINAHL, Academic Search Premier, PsycARTICLES, Psychology \& Behavioral Sciences Collection, Web of Science, and Arctic Health databases for articles published 
between January 1, 2000 to December 31, 2018. The following search words were used: healthy aging, healthy ageing, successful aging, or successful ageing, and perspectives, perceptions, or qualitative research, and Circumpolar North, Arctic, Subarctic, Canada, Finland, Denmark, Greenland, Faroe Islands, Iceland, Norway, Russia, Sweden, or Alaska.

Included studies were published in English and comprised of qualitative research that may have included narratives, experiences, and/or lay perspectives on healthy or successful aging among community-dwelling older adults. Studies were selected if they included people over age 50 years old as interviewees or key informants. "Elder" is defined differently in many immigrant and Indigenous communities of the Circumpolar North. Therefore five articles in this analysis (Collings 2000, 2001; Hopkins et al. 2007; Torres 2001, 2003) included individuals as young as 35-40 years old because that cutpoint made the most sense in those communities between "young" and "old." Since participants in these studies included individuals over the age of 50 they were included in this analysis.

Studies were excluded from this analysis if participants were recruited from nursing homes and institutional settings because those individuals might have complicating medical conditions or social restrictions that could affect their viewpoints. Although these individuals do have important perspectives to be investigated in future research, they are currently outside the scope of this analysis. Review studies, articles dedicated to syntheses of professionals' experiences and perceptions, and studies that quantitatively or objectively tried to measure seniors' successful aging using a medical model were also excluded. Because this process involved many different search iterations and a careful reading of every abstract, 194 articles were assessed for eligibility by the first author, resulting in a total of 23 included articles. The second author then replicated these searches to verify that all possible articles were included.

\section{Analysis}

This systematic review resulted in 23 articles analyzed, which appears to be a reasonable number considering a similar literature review of qualitative studies on older adult perceptions of healthy aging, not focused on any specific region, published in 2013 yielded only 10 studies (Holm and Severinsson 2013). Fortunately, interest in how older adults think about healthy aging has been increasing in the research literature in recent years. Indeed, half of the articles included in this analysis $(N=11)$ were published between 2013 and 2018.

Manuscripts were coded using line-by-line textual coding of the 23 manuscripts in NVivo v. 12 Pro (NVivo qualitative data analysis software, 2018). Using inductive analysis with a grounded theory framework, the authors attached low-inference codes that came organically from the data to text segments consisting of a sentence or paragraph (Card 2015). Low-inference codes are those that are discrete from each other and do not require high levels of value judgments to assign text segments to codes. For example, a code for "transportation" and a code for "health status" require a low-level of inference because they are distinct categories that would not often be confused.

The first author (an anthropologist) coded the first 11 manuscripts, creating and refining a first draft of the codebook. The second author (a psychologist) then coded two of those manuscripts using the codebook, provided feedback, and discussed changes and edits that refined the 2 nd draft of the codebook. The first author then coded the remaining 11 manuscripts and updated the codebook a third time. This 3rd and final draft of the codebook was then used by the second author to code two more manuscripts. Since these inter-disciplinary researchers co-coded $20 \%$ of the manuscripts and achieved $\geq 85 \%$ inter-rater agreement, this qualitative analysis is considered reliable (Bernard 2006; Morse 2015; Neuendorf 2002). 
The data for this manuscript were analyzed using the principles of Grounded Theory (Glaser and Strauss 1967). This method allows for the systematic analysis of data by identifying common concepts and uses an inductive approach to test hypotheses. Using this approach, the data were organized into common themes for comparison across manuscripts. Grounded Theory allows for creation of theories that are driven by the data rather than attempting to fit the data into existing theoretical frameworks. The authors of the current manuscript followed open coding procedures to establish and categorize common themes in the papers reviewed (Strauss and Corbin 1998). Open coding (i.e. initial coding) is considered the basis of Grounded Theory and entails sorting and labeling data and allows for the systematic comparison of qualitative responses (Charmaz 2006).

\section{Results}

Among the 23 included articles are 5 studies from Sweden, 6 from the US (Alaska), 4 from Canada, 2 from Denmark, 2 from Norway, 2 from Finland, one from the Faroe Islands, and one multi-sited study (Sweden and Finland). The articles represent a mixture of ethnic and immigrant groups as well as populations from both rural and urban locations. For example, the Alaskan and Canadian studies consisted of rural, Indigenous populations while the rest of the studies involved non-Indigenous participants. Study sample sizes varied from 9 participants in one Norwegian study to 2579 respondents in the multi-sited study (see Table 1, below). Sampling strategies for most studies were nonrandom (convenience or purposive sampling), while 5 studies utilized random and/or representative samples. ${ }^{15-16,18-20}$ Study participants ranged in age from 38 years old to 98 years old, indicating a wide variety of perspectives on healthy aging represented in these 23 included articles (see Table 1, below).

Study methodologies consisted mostly of semi-structured interviews $(N=19)$ but several included articles also indicated use of community-based participatory research (CBPR) principles, ${ }^{1,9-12}$ card-sorting activities, ${ }^{3-4}$ structured questionnaires/survey instruments that included open-ended questions, ${ }^{16-18,20}$ ethnographic methods, ${ }^{6,14}$ life histories, ${ }^{13,16}$ and vignette discussions. ${ }^{21-22}$ Several themes were extrapolated from this systematic analysis that are consistent with other research on healthy aging perspectives, with three additional themes that may be unique to the Circumpolar North.

\section{Themes}

Participants in the qualitative studies included psychosocial and biomedical aspects, as well as the importance of regular social interaction, in their definitions of healthy aging. The psychosocial aspects mentioned by older adults in these articles included the importance of autonomy and independence, spirituality, and maintaining mental health, such as avoiding depression and adopting an attitude of positivity and gratitude. Participants in 9 studies also indicated the importance of having meaning or purpose-in-life to achieve healthy aging outcomes. ${ }^{4-5,9,12-}$ 13,18,20,21-22

Biomedical definitions of healthy aging among this sample of research study participants included aspects of physical health, cognitive health, and access to healthcare resources. Within physical health concerns, participants often mentioned dealing with the biological changes in their body, the increasing role of pain and illness, and likelihood of frailty or disability. Although some participants in the Circumpolar North indicated that healthy aging 





requires being disability- and illness-free, ${ }^{8}$ one even stating that aging is a process of "languishing in a heap of the useless, “6 a significant portion of respondents in 7 of the articles indicated that it is possible to be healthy despite disease or disability status. ${ }^{3-5,9,15-17}$ In fact, $83.8 \%$ of respondents in the longitudinal Manitoba study self-reported that they have "aged successfully," even though nearly half (47\%) of respondents reported some limitations with instrumental activities of daily living (IADLs). ${ }^{20}$

However, Róin found that in the Faroe Islands, older adults think about aging in two clear categories, those aging well and those not aging well. All participants in the study explicitly or implicitly put themselves into the "healthy aging" category, and referred to themselves as "we" when outlining those practices that keep older adults healthy. When speaking about Elders who might not be aging as well, participants employed the term "them," to distance themselves from this group. The "us" and "them" divide tended to track along moral lines, delineating those who eat well, get physical activity, and stay engaged in community life as those who are aging well and "taking care of themselves" as "one should." Even when participants admitted to a relatively unhealthy practice, they were often careful not to contradict themselves outright, as Róin points out in her discourse analysis.

This review analysis of the Circumpolar North yielded two more components of biomedical health according to older adults in the included studies. Cognitive health was mentioned as a component of healthy aging in 8 articles, referring to the maintenance of intelligence, "to have a good memory,"16 and "keeping your mind sharp"" throughout the life course. Also, among these articles from the Circumpolar North, $26 \%$ of the included studies reported that some older adults are concerned with the role of alcohol and/or substance use in the elder community, 4,8,9-10,13,18 a finding which is not often reported in lay models of aging.

Access to healthcare and the declining quality of eldercare were also mentioned as a problem in the Circumpolar North. Particularly, the older adults in rural Alaska felt that in order to access the care they need as they age they must move to urban areas with greater access to medical providers and specialists that are not available in remote locations. ${ }^{79-12}$ This prospect was viewed to have a chain reaction for Alaska Native Elders, who felt that if they left their communities they would be increasingly isolated in the big city, exposed to dangerous environments, and cut off from accessing traditional foods that maintain their health. As one elder stated,

"In Anchorage they don't have the help of their families too, unless if they bring them with them. Change of food, I noticed that too really, somehow. When I'm in Anchorage, my daughter has to drop me off at the store. When I need to go to the store and if it's a couple blocks away I walk, but it's scary."11

Likewise, residents of Northern Europe appeared to be concerned with the geriatric healthcare workforce shortage and the related declining quality of elder care services in their communities. ${ }^{5-6,18,23}$ Participants in Sweden indicated the likelihood that there will be reduced resources for the provision of eldercare, resulting in lower quality of care. ${ }^{19}$ Thyli et al. demonstrate that older immigrants in Sweden will not utilize eldercare services because they prefer family over paid caregivers stating,

"It is difficult as you get older, the language. And you have the difference between you and us. It is best to make it on our own, and not bother anybody. I don't like being dependent upon others who are outside of the family. Then it is better to speak together in the same language. I end up sitting there alone, having to be accompanied by my daughter. For her, there will be even more to do if she has to go out with me."23 
Indeed, the Alaska Native, Canadian Inuit, and immigrant populations in these studies indicated that family caregivers were preferred over paid caregivers, although such family eldercare tends to fall disproportionately on daughters and other related females..$^{3-4,7,23}$ However, the opposite was true in Sweden, Denmark, and Norway, where older adults utilized paid caregiving services along with their desire to avoid being a "burden" to their family members. $^{5,14-15,19}$ Indeed, most of the analyzed studies $(N=15)$ included the importance of independence and autonomy in the definition of healthy aging, however, these studies were the ones based in Northern Europe. Indigenous and immigrant populations were more likely to indicate the importance of having family supports in order to successfully age-in-place. Taken together, these Circumpolar North studies suggest that this population of older adults prefer their paid or unpaid caregivers to provide competent, friendly, empathic care, much like a family member. ${ }^{5,7,9-12,14,18-19}$

Despite some culturally-specific desires to remain independent, social interactions such as community engagement and making or maintaining interdependent relationships (with family, caregivers, and friend networks) to avoid loneliness and isolation were of substantial importance among all studies in this review. Participants in this Circumpolar North literature also mentioned the role of the broader community and societal views of older persons, such as discrimination and ageism, as having an effect on their own healthy aging. This finding, and many of the themes identified so far in this review, are in line with other studies on successful aging (see, for example, Bowling and Dieppe 2005; Cosco et al. 2013), but the Circumpolar North qualitative literature was largely interwoven with three additional themes: respecting the wisdom of elders, relationship to the natural environment, and psychosocial resilience (see Fig. 1, below).

Although several studies included Indigenous, immigrant, or migrant populations, most studies did not mention language as a barrier. For example, Hopkins et al. conducted their research interviews in English or Cup'ik, depending on participant preference. ${ }^{7}$ Likewise, Thyli et al. mitigated potential language barriers by having participants invite relatives or significant others who could assist with interpretation. ${ }^{23}$ Kulla et al. and Torres' studies included immigrants who had migrated such a long time ago that they were presumably able to complete the study questionnaires and interviews in the dominant language of their country of residence. ${ }^{8,21}$ However, Söderbacka, et al. state that their sample consisted of different language groups (Finnish and Swedish) residing in two different countries, yet the article is unclear whether the questionnaires were available in both languages. ${ }^{18}$ Collings $(2000,2001)$ indicated that several interested Inuit Elders were unable to participate in the studies because they were uncomfortable with their conversational use of English and the study budget did not include the use of interpreters. Collings also included a discussion on the differences in speaking style between the researchers and the participants, stating that answers to questions were rarely given in simple answers but instead required some interpretation of stories. This language barrier also translated to difficulties in conversation and knowledge transmission between Elders and their grandchildren. ${ }^{4-5}$

\section{Respecting the Wisdom of Elders}

Another common theme in the Circumpolar North literature from lay models of healthy aging is the importance for the community to acknowledge and respect the wisdom of older adults. Often this concept is tied to the changing roles of older adults in modern society, where the skillsets of youth tend to be valued more highly than the wisdom that comes with age. One participant in Sweden suggested the need to change the way youth view the process of aging, 


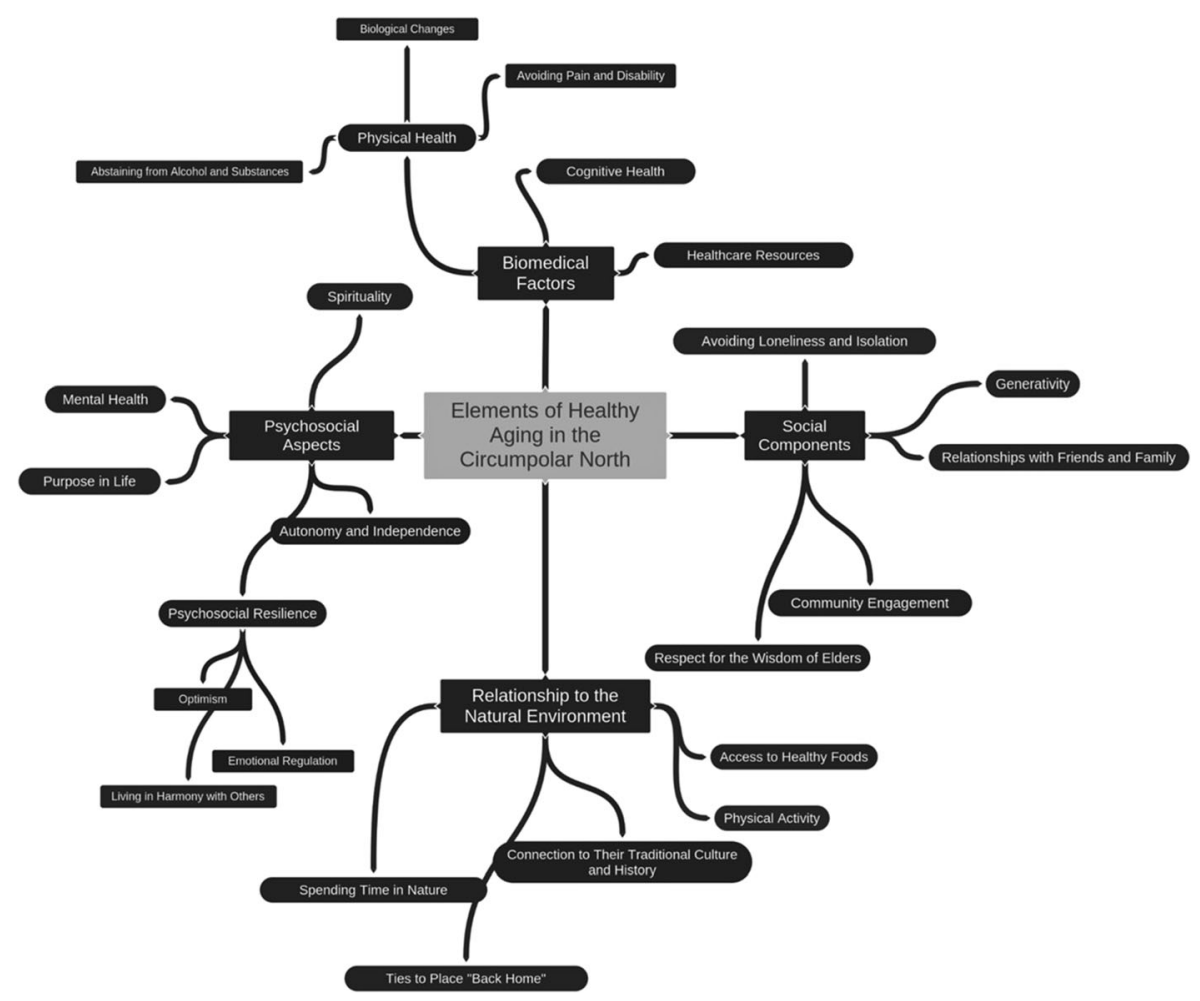

Fig. 1 A concept map of perspectives on healthy aging in the Circumpolar North

"Like I said before when I was younger I thought that old age was something we all needed to fight against .... That is the way it is for most people that think that getting old is an awful thing .... That is why one thinks that something needs to be done to prevent this ... but with age comes wisdom. The body ages, there is nothing that can be done about that so one becomes more realistic." 21

The Alaskan and Canadian studies focused on Indigenous populations, who also tended to speak about wisdom as a defining characteristic of healthy aging. In some cases, a person's chronological age had little to no bearing on their status into Elderhood. Instead possessing wisdom, living a more traditional lifestyle (including subsistence practices like hunting, trapping, fishing, berry gathering, etc.), and sharing that wisdom with the younger generation were important characteristics of healthy aging in these communities..$^{3-4,7,9-12}$ The act of sharing wisdom and knowledge with the younger generation is referred to as generativity in the gerontological literature and it was a pervasive theme among these studies. For example, an 83-year-old male said,

"The best thing I like about being Inutquaq [a Canadian Inuit Elder] is just having the friendship of the other elders of the same generation, the elders around me now. What I enjoy most, too, is being able to talk to young people, people younger than I who have a long life ahead of them, about what life has to offer, what expectations they can have about life, what's good about life, how they can make that life good for themselves."4 
Many older adults expressed their desire to share their life experiences with their children and grandchildren as a way of carrying on their traditions and keeping their values alive. One Alaskan Elder stated, "Well, I think, uh, young people would begin to understand their grandparents' way of life. And follow the pathway of getting your food, and learn the better food values for themselves, I think this would do them well." ${ }^{11}$ An Aleut Elder discussed how we could learn from our Elders and their lifestyle, stating, "That is a good way, from the Elders that you know and how they lived and look at how they are getting along. You try to do likewise." 11

One Elder shared his view on successful aging stating,

"I learned it from grandpappy, something that was passed down through the ages.

Learning what is good, what is bad, what you need to do to age well and the big thing is staying healthy, being outdoors, fresh air, and being active." 12

Likewise, in Norway the creation of the Norwegian national costume for a grandchild's confirmation ceremony created a feeling among a grandmother that, "this is something you're giving to a grandchild and she'll have it for the rest of her life [...] That's a good feeling, compared to embroidering a national costume and selling it to someone you don't know."2 In sharing their knowledge and history, seniors were carrying on traditions they learned from their own Elders when they were younger and viewed as important components of healthy aging.

\section{Maintaining a Relationship to the Natural Environment}

Many people of the Circumpolar north have a special relationship with the land and the natural environment. This is evident in the sharing of traditional values, subsistence lifestyles, and due to the geographical isolation experienced by many in the north. This isolation lends itself to more experience with nature simply due to the vast availability of undeveloped land. In Finland and Sweden, older adults often reflected on their relationship to the land and having access to nature to ensure healthy aging. For example, one elder indicated that, "the seasons, nature, the sun, the sea, flowers, the woods and fields, a breeze, the garden, [the] view of the lake, the mountains give me vitality." 18 Indeed, many people feel a deep connection to the natural environment of the place they call home, even after relocating (Liu, Maher, and Sheer 2019). This relationship to their homeland becomes part of their identity that persists long after leaving their native land. For example, some immigrants to Norway reported that they consulted physicians when visiting their countries of origin. The researchers state that older adults reporting buying prescriptions and other medical supplies "at home," apparently not trusting of the services available in Norway. ${ }^{23}$

Torres (2003) reports on a subset of her Iranian immigrant sample living in Sweden whom indicated the importance of living in harmony with the land in their understandings of successful aging. These respondents believed that nature and humanity are the same, much like some of the Indigenous perspectives from the Alaskan and Canadian studies. They reported beliefs that humans need to co-exist better with the land and that by collaborating with nature people can achieve healthy aging. These were respondents who also believed that one ought to "listen" to their aging body to age successfully, as opposed to trying to "handle it" or "give up." 22

Since several of these articles included studies among Indigenous populations or immigrant populations, older adults in the Circumpolar North seem to have an important relationship with the land that may not be evidence in other studies on healthy aging. For example, as Lewis 
(2014b) stated, "The connection to the land and environment (i.e., subsistence lifestyle) provides a distinct lifestyle of these [Alaska Native] Elders that pose distinct challenges to aging-in-place" in the Circumpolar North. Indeed, access to the land and culturally-appropriate food in urban Canada and Sweden is very different than in rural Canada and Alaska, where participants most strongly stressed the importance of access to food that is culturally meaningful for healthy aging. Participants in these regions were mostly Indigenous and often evoked notions of tradition and history when talking about their native or "country" foods,

"In years back, before I was born, I know there were elders that were very healthy and strong because they have their food, their native food, not mixed up with the kass'aq [white person] food. Although they have a hard life, they were healthy, strong, because of their native food. Seal oil, dried fish."

Indeed, in Canada, one participant stated that the best thing about being an elder "must be when they get food brought to them by the younger people because granny likes it when we bring her food, country food. They must like that. She likes it, anyway."4 Native Canadian and Alaskan participants also connected the importance of traditional physical activities to their native foods in an overall lifestyle that was healthier than they tend to get to live today,

"First of all, it's got to do with the food. That's one of the big factors. In the olden days, when Alaska Natives were eating their own food, like vegetation, meat, or [not] too much caffeine, they would be a lot healthier because at the time, the people were using themselves as a motor, or a kayak, or like, as a machine." 9

Engaging in traditional practices provides many benefits for seniors including reconnecting them with their native land and practices. The physical activity supplies exercise for the body while food that comes from the land provides nutrition and a connection to the land itself.

\section{Developing Psychosocial Resilience}

Participants in these Circumpolar studies described the importance of living a harmonious and balanced life in which older adults get along with their family, friends, neighbors, peers, and are able to effectively regulate their emotions in times of hardship. Healthy coping strategies and psychosocial adaptations included recognizing the importance of living in harmony with their surroundings and emotions through such concepts as having a "rich," "balanced," or "happy" life or "living in peace" as you age. ${ }^{16}$ One indigenous Alaskan described this as "[f]orgiving people and talking about my worries." 10

Older adults in these studies tended to describe their current mindset of gratitude and harmony as being quite different ways of adapting to change and stress compared to when they were younger. ${ }^{18}$ Older adults in many of these studies indicated actively trying to avoid negative actions and thoughts as they have advanced in age. One Elder emphasized the importance of thinking through her feelings and not acting impulsively as a healthy adaptation she has developed, "by not doing what first comes to mind. Even though I may be angry, I try not to do what I really want to do. And holding back what I want to say to others if it will hurt them."10 One Alaska Native Elder stated, "It's good for the Elders not to follow the negative thoughts. Avoid the negative and bad." Avoiding anxiety and worry was stated as an important aspect of healthy aging, "[Elders] that don't worry too much stay young. Ones that worry too much age faster."10 
In addition to regulating emotions, another strategy mentioned by older adults was to recognize their abilities and to make adjustments based on current limitations. Older adults across the Circumpolar North stated the need to accept and respect the biological changes in their bodies by changing the way they think about aging. ${ }^{22}$ As one respondent said, "One must take it easy when one grows old. If you want to be able to live longer you have to slow down ... It is not good to be stressed out about what needs to be done all the time ... not when one is old." 21 Older adults also dealt with memory loss by taking notes during telephone conversations, demonstrating behavioral strategies to cope with age-related changes. ${ }^{15}$ Another way that older adults in the North avoided potentially stressful situations was by planning their daily activities and setting priorities ahead of time, so that they could be prepared for alternative situations that might arise. ${ }^{5}$ Such psychosocial adaptive strategies also included spiritual practices, focusing on hope for the future, setting appropriate goals, investigating their core personal values, and maintaining a sense of humor in the face of adversity. $5,9,15$

The aforementioned strategies to cope with life changes makes the older participants in these Circumpolar North locations appear to be particularly adaptable and resilient. However, participants also recognized that despite their psychosocial resiliency, not all aspects of healthy aging were within their grasp. For example, in Denmark and Sweden, participants recognized that the ability to age healthfully was dependent on their own inner strength as well as the skills of their caregivers and other factors of their physical environment. ${ }^{5-6,15}$

\section{Discussion}

Although researchers are beginning to understand the social and environmental determinants of healthy aging, little is known about how older adults in the Circumpolar North conceptualize aging and how to age healthfully, or "successfully." Therefore, a qualitative, systematic analysis of how older adults define healthy aging in the Circumpolar North is an important addition to the literature because research shows that when respondents create lay models of their community health issues, these models are more inclusive than researcher-driven definitions of healthy aging. Such robust models reveal previously unknown factors that can inform effective health promotion programming in the region to reduce the health disparities that persist in the Circumpolar North. These models provide guidance for caregivers to implement more culturally competent practices and to create treatment systems that are context specific based on the concerns that local elders find essential to their health. A deeper understanding of local needs could improve communication overall and decrease barriers to culturally appropriate treatment.

The results of this literature review indicate that many aspects of healthy aging are common across populations, including a desire for autonomy; mental, cognitive, and physical health; purpose in life; access to healthcare; social relationships; and community engagement. Older adults in the Circumpolar North also focused on the role of society in respecting the wisdom and experiences of elders, their relationship to the natural environment, and psychosocial resilience, such as optimism, balancing their emotions, and living in harmony with others.

In many modern societies, the social role of older adults has often changed from a place of prominence in the family or community to a role on the margins (Charles and Carstensen 2010). Despite this reality, which can also be termed "role loss" (Elwell and Maltbie-Crannell 1981), Indigenous populations of the Circumpolar North still retain core traditional values, such as acknowledging the wisdom of Elders (Lyons 2010). Even among populations of non- 
Indigenous peoples of the North, older adults in these analyzed studies indicated that respecting the wisdom of older adults was an important feature of their own healthy aging. Older adults expressed a desire for younger people to seek guidance and knowledge from the older generation, because such intergenerational experiences put older adults in the meaningful role of teachers in their communities.

Of course, teaching others is considered a meaningful experience for both parties involved (McAdams et al. 1993). However, older adults who are able to teach younger people what they have learned often find such generative experiences to increase their meaning and purpose in life, which is linked to longevity and better health outcomes (Carlson et al. 2000; Gruenewald et al. 2012). Before generativity can begin to take place, it may be necessary for many societies to improve the way their younger generations view older populations. When elder abuse, financial scams, and negative (or ageist) stereotypes abound, it may be very difficult for older adults to gain the respect they need in order to be valued members of society with the ability to age healthfully.

Participants in the analyzed studies also valued their relationship to nature. Although researchers may be aware of the health benefits of spending time outdoors in nature (Gladwell et al. 2013; Jacobs et al. 2008) especially for children (Kruger et al. 2010), it is not always mentioned as a necessity among older adults to define healthy aging. In the Circumpolar North, the importance of the land takes special shape for Elders, who expressed their desire to spend more time outdoors engaged in physical activities (Howell and Bardach 2018; Lewis 2013a) which may include walking, hiking, or engaging in food procurement (subsistence activities).

Relatedly, older adults articulated their relationship to the land when they stressed the importance of place for their ability to age healthfully. Participants in the analyzed studies may have been speaking about their yearning to return home where food, medicine, and social supports were more familiar (in the case of migrants) or their desire to avoid moving and agein-place. Research shows that older adults often experience several relocation events as they get older, both voluntarily and involuntarily, which can be extremely stressful experiences (Pope and Kang 2010; Stoeckel and Porell 2010; Svidén et al. 2002). Indeed, much recent work has demonstrated that older adults largely wish to age-in-place, rather than relocate, where they feel connected to their home, community, and family (Bigonnesse et al. 2014; Gott et al. 2004; Wiles et al. 2012).

The connection with nature and the land has been important to humans throughout history. The therapeutic benefits of nature have been shown in a multitude of studies (Selhub and Logan 2012; for review see Mantler and Logan, 2015 and Pearson and Craig, 2014). Wilson (1984) called this inherent relationship with nature and other living creatures biophilia. There is a strong belief that the human relationship with nature is both beneficial and fundamentally necessary for healthy functioning. Kahn et al. (2009) stated that "Humans cannot achieve full measure of sensibility and meaning apart from the natural world." Exposure to nature has been shown to improve physical (Brown et al., 2016; de Vries, et al., 2003; Korpela and Ylen, 2008, Pretty 2004), mental and cognitive well- being (Bratman et al., 2015; Kaplan and Talbot 1983; for review see Bratman, Hamilton, and Daily 2012) as well as providing stress relief (McFarland, Waliczek, and Zajicek, 2010) and a feeling of restoration (Kaplan 1989).

Resilience is another defining feature of healthy aging in the Circumpolar North. However, some argue that the term "resilience" does not adequately address the process of adaptation experienced by elders in the Circumpolar North (Akearok et al. 2019). This argument is largely based on differences in methodology and a predominately Westernized definition of adversity. Akearok et al. (2019) contend that these beliefs differ from the more spiritually-derived 
definitions of most Arctic Indigenous people who describe a connection with traditional values and practices. Moreover, those authors criticized most evaluations of resilience for using a predetermined, Westernized definition of resilience and conducting primarily quantitative studies. The current review found that psychosocial resilience is an important factor in healthy aging as described by northern Elders. The articles reviewed here contained a number of studies with Indigenous participation and examined qualitative studies, where participants were able to define and explain their responses in detail. Because of these factors, the concept of psychosocial resilience seems aptly applied to the Circumpolar North as demonstrated in the reviewed studies.

This review paper demonstrates that in addition to the biomedical and psychosocial aspects of health that can often be found across the healthy aging literature, older adults in the Circumpolar North have some unique challenges and opportunities. Since there is a sizeable Indigenous population in the region, cross-cultural transmission of valuing the wisdom of elders and respecting the relationship to the land can help improve the quality of life of all older adults in the Circumpolar North. Additionally, this study shows that future research can focus on existing strengths, such as psychosocial resilience, in the region. This analysis also highlights the need for increased translational research with populations in the Circumpolar North that are under-represented in the literature.

Acknowledgements Support provided by the Alaska EPSCoR National Science Foundation award \#OIA1757348 and the state of Alaska. The authors wish to thank Ruby Fried and the anonymous reviewers for providing valuable feedback on earlier drafts of this article.

Funding Information This study was funded by Alaska EPSCoR NSF award \#OIA-1757348.

\section{Compliance with Ethical Standards}

Conflict of Interest The authors declare that they have no conflict of interest.

\section{References}

Abarca-Gómez, L., Abdeen, Z. A., Hamid, Z. A., Abu-Rmeileh, N. M., Acosta-Cazares, B., Acuin, C., Adams, R. J., Aekplakorn, W., Afsana, K., \& Aguilar-Salinas, C. A. (2017). Worldwide trends in body-mass index, underweight, overweight, and obesity from 1975 to 2016: A pooled analysis of 2416 population-based measurement studies in 128. 9 million children, adolescents, and adults. The Lancet, 390(10113), 26272642.

Abass, K., Emelyanova, A., \& Rautio, A. (2018). Temporal trends of contaminants in Arctic human populations. Environmental Science and Pollution Research, 25(29), 28834-28850. https://doi.org/10.1007/s11356-0182936-8.

Akearok, G. H., Stoor, J., Kanayurak, N., Rink, E., Emelyanova, A., Larsen, C., Cueva, K., \& Hiratsuka, V. (2019). Exploring the term "resilience" in Arctic health and well-being using a sharing circle as a community-centered approach: Insights from a conference workshop. Social Sciences, 8(2), 45. https://doi.org/10.3390/socsci8020045.

Aslaksen, I., Dallmann, W., Holen, D. L., Høydahl, E., Kruse, J., Stapleton, M., \& Turi, E. I. (2008). Interdependency of subsistence and market economies in the Arctic. The Economy of the North, 2007, 75-98. https://doi.org/10.1684/pnv.2011.0285.

Bacsu, J., Jeffery, B., Abonyi, S., Johnson, S., Novik, N., Martz, D., \& Oosman, S. (2014). Healthy aging in place: Perceptions of rural older adults. Educational Gerontology, 40(5), 327-337. https://doi.org/10.1080 /03601277.2013.802191. 
Bardage, C., Pluijm, S. M. F., Pedersen, N. L., Deeg, D. J. H., Jylhä, M., Noale, M., Blumstein, T., \& Otero, Á. (2005). Self-rated health among older adults: A cross-national comparison. European Journal of Ageing, 2(2), 149-158. https://doi.org/10.1007/s10433-005-0032-7.

Bauger, L., \& Bongaardt, R. (2016). The lived experience of well-being in retirement : A phenomenological study. International Journal of Qualitative Studies on Health and Well-Being, 11, 33110. https://oi. org/10.3402/qhw.v11.33110.

Begum, S., \& Naskali, P. (2016). Challenges to the human security of elderly Sámi in Finnish and Swedish Lapland. In: K. Hossain and A. Petretei (Eds.), Understanding the Many Faces of Human Security: Perspectives of Northern Indigenous Peoples (pp. 211-229). Netherlands: Brill Nijhoff.

Bernard, H. R. (2006). 2006 Research methods in anthropology (4th ed.). New York: AltaMira.

Bigonnesse, C., Beaulieu, M., \& Garon, S. (2014). Meaning of home in later life as a concept to understand older adults' housing needs: Results from the 7 age-friendly cities pilot project in Québec. Journal of Housing for the Elderly, 28(4), 357-382. https://doi.org/10.1080/02763893.2014.930367.

Bjerregaard, P., \& Dahl-Petersen, I. K. (2011). How well does social variation mirror secular change in prevalence of cardiovascular risk factors in a country in transition? American Journal of Human Biology, 23(6), 774-779. https://doi.org/10.1002/ajhb.21209.

Boudiny, K. (2013). 'Active ageing': From empty rhetoric to effective policy tool. Ageing and Society, 33(6), 1077-1098. https://doi.org/10.1017/S0144686X1200030X.

Bourque, F., \& Cunsolo Willox, A. (2014). Climate change: The next challenge for public mental health? International Review of Psychiatry, 26(4), 415-422. https://doi.org/10.3109/09540261.2014.925851.

Bowling, A. (2005). Ageing well: Quality of life in old age. Maidenhead: Open University Press.

Bowling, A. (2006). Lay perceptions of successful ageing: Findings from a national survey of middle aged and older adults in Britain. European Journal of Ageing, 3(3), 123-136. https://doi.org/10.1007/s10433-0060032-2.

Bowling, A., \& Dieppe, P. (2005). What is successful ageing and who should define it? BMJ (Clinical Research Ed.), 331(7531), 1548-1551. https://doi.org/10.1136/bmj.331.7531.1548.

Bratman, G. N., Hamilton, J. P., \& Daily, G. C. (2012). The impacts of nature experience on human cognitive function and mental health. Ann N Y Acad Sci, 1249, 118-136. https://doi.org/10.1111/j.17496632.2011.06400.x.

Bratman, G. N., Daily, G. C., Levy, B. J., \& Gross, J. J. (2015). The benefits of nature experience: Improved affect and cognition. Landscape and Urban Planning, 138, 41-50.

Brega, A. G., Ang, A., Vega, W., Jiang, L., Beals, J., Mitchell, C. M., Moore, K., Manson, S. M., Acton, K. J., \& Roubideaux, Y. (2012). Mechanisms underlying the relationship between health literacy and glycemic control in American Indians and Alaska natives. Patient Education and Counseling, 88(1), 61-68. https://doi.org/10.1016/J.PEC.2012.03.008.

Brown, S. C., Lombard, J., Wang, K., Byrne, M. M., Toro, M., Plater-Zyberk, E., Feaster, D. J., Kardys, J., Nardi, M. I., Perez-Gomez, G., Pantin, H. M., \& Azapocznik, J. (2016). Neighborhood greenness and chronic health conditions in Medicare beneficiaries. American Journal of Preventive Medicine, 51(1), 78-89.

Card, N. A. (2015). Applied meta-analysis for social science research. New York: Guilford Publications.

Carlson, M. C., Seeman, T., \& Fried, L. P. (2000). Importance of generativity for healthy aging in older women. Aging Clinical and Experimental Research, 12(2), 132-140. https://doi.org/10.1007/BF03339899.

Charles, S. T., \& Carstensen, L. L. (2010). Social and emotional aging. Annual Review of Psychology, 61, 383409. https://doi.org/10.1146/annurev.psych.093008.100448.

Charmaz, K. (2006). Constructing grounded theory: A practical guide through qualitative analysis. Thousand Oaks: Sage.

Collings, P. (2000). Aging and life course development in an Inuit community. Arctic Anthropology, 37(2), 111125.

Collings, P. (2001). "If you got everything, it's good enough": Perspectives on successful aging in a Canadian Inuit community. Journal of Cross-Cultural Gerontology, 16(2), 127-155. https://doi.org/10.1023 /A:1010698200870.

Cosco, T. D., Prina, A. M., Perales, J., Stephan, B. C. M., \& Brayne, C. (2013). Lay perspectives of successful ageing: A systematic review and meta-ethnography. BMJ Open, 3(6), 1-9. https://doi.org/10.1136/bmjopen2013-002710.

Cunsolo Willox, A., Stephenson, E., Allen, J., Bourque, F., Drossos, A., Elgarøy, S., Kral, M. J., Mauro, I., Moses, J., Pearce, T., MacDonald, J. P., \& Wexler, L. (2015). Examining relationships between climate change and mental health in the circumpolar north. Regional Environmental Change, 15(1), 169-182. https://doi.org/10.1007/s10113-014-0630-Z.

de Vries, S., Verheij, R. A., Groenewegen, P. P., \& Spreeuwenberg, P. (2003). Natural environments-healthy environments? an exploratory analysis of the relationship between greenspace and health. Environment and Planning A: Economy and Space, 35(10), 1717-1731. https://doi.org/10.1068/a35111. 
Driscoll, D. L., Dotterrer, B., \& Brown II, R. A. (2013). Assessing the social and physical determinants of circumpolar population health. International Journal of Circumpolar Health, 72. https://doi.org/10.3402 /ijch.v72i0.21400.

Elwell, F., \& Maltbie-Crannell, A. D. (1981). The impact of role loss upon coping resources and life satisfaction of the elderly. Journal of Gerontology, 36(2), 223-232. https://doi.org/10.1093/geronj/36.2.223.

Emelyanova, A., \& Rautio, A. (2016). Population diversification in demographics, health, and living environments: The Barents region in review. Nordia Geographical Publications, 45(2), 3-18.

Emelyanova, A., Golubeva, E., \& Danilova, R. (2010). The aging process as a part of human development in the high north. Bold, 20(2), 22-30.

Entwistle, V. A., Renfrew, M. J., Yearley, S., Forrester, J., \& Lamont, T. (1998). Lay perspectives: Advantages for health research. BMJ (Clinical Research Ed.), 316(7129), 463-466

Foutz, J. D., Cohen, S. A., \& Cook, S. K. (2016). Challenges and barriers to health care and overall health in older residents of Alaska: Evidence from a national survey. International Journal of Circumpolar Health, 75(1), 30348. https://doi.org/10.3402/ijch.v75.30348.

From, I., Johansson, I., \& Athlin, E. (2007). Experiences of health and well-being, a question of adjustment and compensation - Views of older people dependent on community care. International Journal of Older People Nursing, 2(4), 278-287. https://doi.org/10.1111/j.1748-3743.2007.00089.x.

Gladwell, V. F., Brown, D. K., Wood, C., Sandercock, G. R., \& Barton, J. L. (2013). The great outdoors: How a green exercise environment can benefit all. Extreme Physiology \& Medicine, 2(1), 3. https://doi.org/10.1186 /2046-7648-2-3.

Glaser, B. G., \& Strauss, A. L. (1967). The discovery of grounded theory: Strategies for qualitative research. Chicago: Aldine.

Gott, M., Seymour, J., Bellamy, G., Clark, D., \& Ahmedzai, S. (2004). Older people's views about home as a place of care at the end of life. Palliative Medicine, 18(5), 460-467. https://doi.org/10.1191/0269216304 pm889oa.

Grøn, L. (2016). Old age and vulnerability between first, second and third person perspectives. Ethnographic explorations of aging in contemporary Denmark. Journal of Aging Studies, 39, 21-30. https://doi. org/10.1016/j.jaging.2016.09.002.

Gruenewald, T. L., Liao, D. H., \& Seeman, T. E. (2012). Contributing to others, contributing to oneself: Perceptions of generativity and health in later life. The Journals of Gerontology Series B: Psychological Sciences and Social Sciences, 67(6), 660-665. https://doi.org/10.1093/geronb/gbs034.

Hansen-Kyle, L. (2005). A concept analysis of healthy aging. Nursing Forum, 40(2), 45-57. https://doi. org/10.1111/j.1744-6198.2005.00009.x.

Holm, A. L., \& Severinsson, E. (2013). A qualitative systematic review of older persons' perceptions of health, ill health, and their community health care needs. Nursing Research and Practice, 2013, 672702-672712. https://doi.org/10.1155/2013/672702.

Hopkins, S. E., Kwachka, P., Lardon, C., \& Mohatt, G. V. (2007). Keeping busy: A Yup'ik/Cup'ik perspective on health and aging. International Journal of Circumpolar Health, 66(1), 42-50.

Howell, B. M., \& Bardach, S. (2018). "It's a social thing:" sociocultural experiences with nutrition and exercise in Anchorage, Alaska. Arctic Anthropology, 55(2), 1-16.

Hung, L.-W., Kempen, G. I. J. M., \& De Vries, N. K. (2010). Cross-cultural comparison between academic and lay views of healthy ageing: A literature review. Ageing and Society, 30(08), 1373-1391. https://oi. org/10.1017/S0144686X10000589.

IPCC. (2014). AR5 Climate change 2014: impacts, adaptation, and vulnerability. Retrieved on February 24, 2019 from https://www.ipcc.ch/report/ar5/wg2/. Accessed 24 Feb 2019.

Jacobs, J. M., Cohen, A., Hammerman-Rozenberg, R., Azoulay, D., Maaravi, Y., \& Stessman, J. (2008). Going outdoors daily predicts long-term functional and health benefits among ambulatory older people. Journal of Aging and Health, 20(3), 259-272. https://doi.org/10.1177/0898264308315427.

Johnson, J. S., Nobmann, E. D., Asay, E., \& Lanier, A. P. (2009). Developing a validated Alaska native food frequency questionnaire for western Alaska, 2002-2006. International Journal of Circumpolar Health, 68(2), 99-108. https://doi.org/10.3402/ijch.v68i2.18319.

Kachan, D., Tannenbaum, S. L., Olano, H. A., LeBlanc, W. G., McClure, L. A., \& Lee, D. J. (2014). Geographical variation in health-related quality of life among older US adults, 1997-2010. Preventing Chronic Disease, 11, E110. https://doi.org/10.5888/pcd11.140023.

Kahn Jr., P. H., Severson, R. L., \& Ruckert, J. H. (2009). The human relation with nature and technological nature. Current Directions in Psychological Science, 18(1), 37-42.

Kaplan, R., \& Kaplan, S. (1989). The experience of nature: A psychological perspective. New York, NY, US: Cambridge University Press. 
Kaplan, S., \& Talbot, J. F. (1983). Psychological benefits of a wilderness experience. In I. Altman \& J. F. Wohlwil (Eds.), Behavior and the natural environment (pp. 163-203). New York: Plenum. https://oi. org/10.1007/978-1-4613-3539-9 6.

Korpela, K. M., Ylen, M., Tyrvainen, L., \& Silvennoinen, H. (2008). Determinants of restorative experiences in everyday favorite places. Health Place, 14(4), 636-652. https://doi.org/10.1016/j.healthplace.2007.10.008.

Kowal, P., Kahn, K., Ng, N., Naidoo, N., Abdullah, S., Bawah, A., Binka, F., Chuc, N. T. K., Debpuur, C., Ezeh, A., Xavier Gómez-Olivé, F., Hakimi, M., Hirve, S., Hodgson, A., Juvekar, S., Kyobutungi, C., Menken, J., Van Minh, H., Mwanyangala, M. A., et al. (2010). Ageing and adult health status in eight lower-income countries: The INDEPTH WHO-SAGE collaboration. Global Health Action, 3(1), 5302. https://doi. org/10.3402/gha.v3i0.5302.

Kruger, J., Nelson, K., Klein, P., McCurdy, L. E., Pride, P., \& Carrier Ady, J. (2010). Building on partnerships: Reconnecting kids with nature for health benefits. Health Promotion Practice, 11(3), 340-346. https://doi. org/10.1177/1524839909348734.

Kulla, G., Ekman, S.-L., \& Sarvimäki, A. (2010). Experiential health from an ageing and migration perspective: The case of older Finland-swedes. Journal of Immigrant and Minority Health, 12(1), 93-99. https://doi. org/10.1007/s10903-008-9133-7.

Kusumastuti, S., Derks, M. G. M., Tellier, S., Di Nucci, E., Lund, R., Mortensen, E. L., \& Westendorp, R. G. J. (2016). Successful ageing: A study of the literature using citation network analysis. Maturitas, 93, 4-12. https://doi.org/10.1016/J.MATURITAS.2016.04.010.

Lewis, J. P. (2011). Successful aging through the eyes of Alaska native elders. What it means to be an elder in Bristol Bay. AK. Gerontologist, 51(4), 540-549. https://doi.org/10.1093/geront/gnr006.

Lewis, J. P. (2013a). The importance of optimism in maintaining healthy aging in rural Alaska. Qualitative Health Research, 23(11), 1521-1527. https://doi.org/10.1177/1049732313508013.

Lewis, J. P. (2013b). The future of successful aging in Alaska. International Journal of Circumpolar Health, 72(1), 21186. https://doi.org/10.3402/ijch.v72i0.21186.

Lewis, J. P. (2014a). The role of social engagement in the definition of successful ageing among Alaska native elders in Bristol Bay, Alaska. Psychology \& Developing Societies, 26(2), 263-290. https://doi.org/10.1177 /0971333614549143.

Lewis, J. P. (2014b). What successful aging means to Alaska natives: Exploring the reciprocal relationship between the health and well-being of Alaska native elders. International Journal of Aging and Society, 3, 77-88.

Lewis, J. P., \& Allen, J. (2017). Alaska native elders in recovery: Linkages between indigenous cultural generativity and sobriety to promote successful aging. Journal of Cross-Cultural Gerontology, 32(2), 209-222. https://doi.org/10.1007/s10823-017-9314-8.

Liotta, G., Canhao, H., Cenko, F., Cutini, R., Vellone, E., Illario, M., Kardas, P., Poscia, A., Sousa, R. D., \& Palombi, L. (2018). Active ageing in Europe: Adding healthy life to years. Frontiers in Medicine, 5, 123.

Liu, S., Maher, J., \& Sheer, V. C. (2019). Through the eyes of older chinese immigrants: identity, belonging and home in a foreign land. China Media Research, 15(2), 39-49.

Liu, J., Young, T. K., Zinman, B., Harris, S. B., \& Connelly, P. W. (2006). Lifestyle variables, non-traditional cardiovascular risk factors, and the metabolic syndrome in an aboriginal Canadian population. Obesity, 14(3), 500-508. https://doi.org/10.1038/oby.2006.65.

Löckenhoff, C. E., De Fruyt, F., Terracciano, A., McCrae, R. R., De Bolle, M., Costa, P. T., Aguilar-Vafaie, M. E., Ahn, C., Ahn, H., Alcalay, L., Allik, J., Avdeyeva, T. V., Barbaranelli, C., Benet-Martinez, V., Blatný, M., Bratko, D., Cain, T. R., Crawford, J. T., Lima, M. P., et al. (2009). Perceptions of aging across 26 cultures and their culture-level associates. Psychology and Aging, 24(4), 941-954. https://doi.org/10.1037/a0016901.

Loring, P. A., \& Gerlach, S. C. (2009). Food, culture, and human health in Alaska: An integrative health approach to food security. Environmental Science and Policy, 12(4), 466-478. https://doi.org/10.1016/j. envsci.2008.10.006.

Lyons, N. (2010). The wisdom of elders: Inuvialuit social memories of continuity and change in the twentieth century. Arctic Anthropology, 47(1), 22-38. https://doi.org/10.1353/arc.0.0034.

Mantler, A., \& Logan, A. C. (2015). Natural environments and mental health. Advances in Integrative Medicine, 2(1), 5-12.

McAdams, D. P., de St. Aubin, E., \& Logan, R. L. (1993). Generativity among young, midlife, and older adults. Psychology and Aging, 8(2), 221-230. https://doi.org/10.1037/0882-7974.8.2.221.

McFarland, A. L., Waliczek, T. M., \& Zajicek, J. M. (2010). Graduate student use of campus green spaces and the impact on their perceptions of quality of life. HortTechnology hortte, 20(1), 186-192. https://doi. org/10.21273/HORTTECH.20.1.186

Mead, E., Gittelsohn, J., Kratzmann, M., Roache, C., \& Sharma, S. (2010). Impact of the changing food environment on dietary practices of an Inuit population in Arctic Canada. Journal of Human Nutrition and Dietetics, 23(SUPPL. 1), 18-26. https://doi.org/10.1111/j.1365-277X.2010.01102.x. 
Mikkelsen, H. H. (2016). Unthinkable solitude: Successful aging in Denmark through the Lacanian real. Ethos, 44(4), 448-463. https://doi.org/10.1111/etho.12144.

Mikow, E., Gonzalez, D., \& Braem, N. (2019). "We used to have whole winters up here:" vulnerability and resiliency of subsistence economies in the Arctic. 46th Annual Meeting of the Alaska Anthropological Association, February 27 - March 2, 2019.

Minkler, M., \& Fadem, P. (2002). "Successful aging:" a disability perspective. Journal of Disability Policy Studies, 12(4), 229-235. https://doi.org/10.1177/104420730201200402.

Miyawaki, C. E. (2015). Association of social isolation and health across different racial and ethnic groups of older Americans. Ageing and Society, 35(10), 2201-2228. https://doi.org/10.1017/S0144686X14000890.

Morse, J. M. (2015). Critical analysis of strategies for determining rigor in qualitative inquiry. Qualitative Health Research, 25(9), 1212-1222. https://doi.org/10.1177/1049732315588501.

Naskali, P., Harbison, J. R., \& Begum, S. (2019). New challenges to ageing in the rural north: A critical interdisciplinary perspective 22. Switzerland: Springer Nature.

Neuendorf, K. A. (2002). The content analysis guidebook. Los Angeles: Sage Publications.

Nilsson, I., Lundgren, A. S., \& Liliequist, M. (2012). Occupational well-being among the very old. Journal of Occupational Science, 19(2), 115-126. https://doi.org/10.1080/14427591.2011.595894.

Nosraty, L., Jylhä, M., Raittila, T., \& Lumme-Sandt, K. (2015). Perceptions by the oldest old of successful aging, vitality 90+ study. Journal of Aging Studies, 32, 50-58. https://doi.org/10.1016/j.jaging.2015.01.002.

Pearson, D. G., \& Craig, T. (2014). The great outdoors? Exploring the mental health benefits of natural environments. Frontiers in Psychology, 5(1178), 1-4.

Pope, N. D., \& Kang, B. (2010). Residential relocation in later life: A comparison of proactive and reactive moves. Journal of Housing for the Elderly, 24(2), 193-207. https://doi.org/10.1080/02763891003757122.

Pretty, J. (2004). How nature contributes to mental and physical health. Spirituality and Health International, $5(2), 68-78$.

NVivo qualitative data analysis software. (2018). QSR International Pty Ltd. Version 12.

Redvers, J., Bjerregaard, P., Eriksen, H., Fanian, S., Healey, G., Hiratsuka, V., Jong, M., Larsen, C. V. L., Linton, J., Pollock, N., Silviken, A., Stoor, P., \& Chatwood, S. (2015). A scoping review of indigenous suicide prevention in circumpolar regions. International Journal of Circumpolar Health, 74(1), 27509. https://oi. org/10.3402/ijch.v74.27509.

Róin, Á. (2014). Embodied ageing and categorisation work amongst retirees in the Faroe Islands. Journal of Aging Studies, 31, 83-92. https://doi.org/10.1016/J.JAGING.2014.09.001.

Rowe, J. W., \& Kahn, R. L. (1997). Successful aging. The Gerontologist, 37(4), 433-440.

Selhub, E. M., \& Logan, A. C. (2012). Your brain on nature: The science of nature's influence on your health, happiness and vitality. John Wiley \& Sons.

Sharma, S. (2010). Assessing diet and lifestyle in the Canadian Arctic Inuit and Inuvialuit to inform a nutrition and physical activity intervention programme. Journal of Human Nutrition and Dietetics, 23(SUPPL. 1), 517. https://doi.org/10.1111/j.1365-277X.2010.01093.x.

Smith, J., Easton, P. S., \& Saylor, B. L. (2009). Inupiaq elders study: Aspects of aging among male and female elders. International Journal of Circumpolar Health, 68(2), 182-196. https://doi.org/10.3402/ijch.v68 i2.18323.

Söderbacka, T., Nyström, L., \& Fagerström, L. (2017). Older persons' experiences of what influences their vitality - A study of 65- and 75-year-olds in Finland and Sweden. Scandinavian Journal of Caring Sciences, 31(2), 378-387. https://doi.org/10.1111/scs.12357.

Söderhamn, O., Skisland, A., \& Herrman, M. (2011). Self-care and anticipated transition into retirement and later life in a nordic welfare context. Journal of Multidisciplinary Healthcare, 4, 273-279. https://doi.org/10.2147 /JMDH.S21385.

Stoeckel, K. J., \& Porell, F. (2010). Do older adults anticipate relocating? Journal of Applied Gerontology, 29(2), 231-250. https://doi.org/10.1177/0733464809335595.

Strauss, A., \& Corbin, J. (1998). Basics of qualitative research techniques. Thousand Oaks: Sage publications.

Svidén, G., Wikström, B.-M., \& Hjortsjö-Norberg, M. (2002). Elderly persons' reflections on relocating to living at sheltered housing. Scandinavian Journal of Occupational Therapy, 9(1), 10-16. https://doi.org/10.1080 /110381202753505818.

Tate, R. B., Lah, L., \& Cuddy, T. E. (2003). Definition of successful aging by elderly Canadian males: The Manitoba followuUp study. The Gerontologist, 43(5), 735-744. https://doi.org/10.1093/geront/43.5.735.

The University of the Arctic. (2018). The Circumpolar North. Retrieved on October 11, 2019 from https://education.uarctic.org/circumpolar-north/ . Accessed 11 Oct 2019.

Thyli, B., Hedelin, B., \& Athlin, E. (2014). Experiences of health and care when growing old in Norway - From the perspective of elderly immigrants with minority ethnic backgrounds. Clinical Nursing Studies, 2(3), 52. https://doi.org/10.5430/cns.v2n3p52. 
Torres, S. (2001). Understandings of successful ageing in the context of migration: The case of Iranian immigrants in Sweden. Ageing and Society, 21(3), 333-355. https://doi.org/10.1017/S0144686X01008261.

Torres, S. (2003). A preliminary empirical test of a culturally relevant theoretical framework for the study of successful aging. Journal of Cross Cultural Gerontology, 18(1995), 79-100.

Waits, A., Emelyanova, A., Oksanen, A., Abass, K., \& Rautio, A. (2018). Human infectious diseases and the changing climate in the Arctic. Environment International, 121, 703-713.

WHO. (2002). Active ageing: A policy framework. WHO.

Wiles, J. L., Leibing, A., Guberman, N., Reeve, J., \& Allen, R. E. S. (2012). The meaning of \&quot;aging in place\&quot; to older people. The Gerontologist, 52(3), 357-366. https://doi.org/10.1093/geront/gnr098.

Wilson, E. O. (1984). Biophilia: the human bond with other species. Harvard: Harvard University Press.

Young, T. K., Kelly, J. J., Friborg, J., Soininen, L., \& Wong, K. O. (2016). Cancer among circumpolar populations: An emerging public health concern. International Journal of Circumpolar Health, 75(1), 29787.

Zunzunegui, M.-V., Alvarado, B.-E., Béland, F., \& Vissandjee, B. (2009). Explaining health differences between men and women in later life: A cross-city comparison in Latin America and the Caribbean. Social Science \& Medicine, 68(2), 235-242. https://doi.org/10.1016/J.SOCSCIMED.2008.10.031.

Publisher's Note Springer Nature remains neutral with regard to jurisdictional claims in published maps and institutional affiliations. 